\title{
CURRÍCULO POR COMPETÊNCIAS: (DES)ENCONTROS ENTRE OS DISCURSOS OFICIAL E PEDAGÓGICO
}

\section{COMPETENCE-BASED CURRICULUM: (DIS)AGREEMENT BETWEEN OFFICIAL AND PEDAGOGICAL DISCOURSES}

Resumo: Neste artigo, focalizamos discursos oficiais da educação e discursos de professores integrantes do Núcleo Docente Estruturante (NDE) de Cursos de Letras de uma universidade pública, com o objetivo de analisar a reação-resposta desses professores à prescrição legal de organização do currículo com base no conceito de competência. Para tanto, analisamos as Diretrizes Curriculares Nacionais para os Cursos de Letras e Formação de Professores e o Projeto Pedagógico do Curso de Letras Português e Literatura da instituição pesquisada, reformulado pelos professores do NDE. Orientam a pesquisa pressupostos bakhtinianos, bem como outros aportes teóricos levantados para construir inteligibilidades sobre os dados. De modo geral, o estudo do Projeto Pedagógico do Curso de Letras Português e Literatura sinaliza que a proposta curricular elaborada pelos sujeitos da pesquisa apresenta caráter próprio, produzindo sentidos diferenciados dos das Diretrizes, no que diz respeito à noção de competência como princípio de organização curricular.

Palavras-chave: Diretrizes Curriculares Nacionais. Projeto Pedagógico de Curso. Responsividade.

\begin{abstract}
In this article, we focus on official discourses of education and discourses of professors from the Structuring Professoriate Groups (NDE) of the Language Teacher Education Undergraduate Program at a public university, aiming to analyze these professors' reaction-response to legal prescriptions of curricular organization based on the concept of competence. Therefore, we analyzed the National Curricula Guidelines for the Language Teacher Education and Training Undergraduate Program and the Pedagogical Project of the Literature and Portuguese of the institution researched, reformulated by the NDE professors. Bakhtinian assumptions, as well as other theoretical contributions collected to build intelligibility about the data, guide the research. Overall, the Pedagogical Project study of the Literature and Portuguese Language Teacher Education Undergraduate Programs indicates that the curricular proposal elaborated by the research subjects has its own character, producing different meanings from those of the Guidelines, in relation to the notion of competence as a curricular organization principle.
\end{abstract}

Keywords: National Curriculum Guidelines. Pedagogical Course Project. Responsiveness.

1 Universidade Federal de Mato Grosso (UFMT), Cuiabá, Mato Grosso, Brasil; jozanes@globo.com; https://orcid.org/0000-0002-4299-4037 
- Currículo por competências: (des)encontros entre os discursos oficial e pedagógico

\section{Introdução}

Este trabalho versa sobre alguns resultados de uma pesquisa de doutorado que buscou compreender a complexidade do processo de reforma de cursos de Letras na esfera acadêmica, a partir do estabelecimento de relações dialógicas entre discursos de professores integrantes do Núcleo Docente Estruturante (NDE) de cursos de Letras de uma universidade pública mato-grossense e discursos oficiais da educação que dispõem sobre a reestruturação curricular de cursos de licenciatura (NUNES, 2017). O NDE é uma instância colegiada constituída por um grupo de professores com atribuições de formulação e acompanhamento do Projeto Pedagógico de um curso de graduação, formalmente indicado pela instituição (BRASIL, 2010).

Dentre os cursos de graduação presenciais ofertados pela instituição pesquisada, cinco são da área de Letras, a saber: Português e Literatura, Português e Francês, Português e Inglês, Português e Espanhol e, a partir de 2014, Letras-Libras. Com exceção desse último, todos os cursos tiveram os projetos pedagógicos reestruturados, no período de 2014 a 2015, tendo o Núcleo Docente Estruturante como responsável pela reformulação. Um dos fatores que impulsionaram tal reestruturação foi o desempenho insuficiente dos cursos no Conceito Preliminar de Curso do Exame Nacional de Desempenho de Estudante (ENADE) de 2011.

Conforme prescrição da Resolução CONAES n. 1/2010, uma das atribuições do NDE é "zelar pelo cumprimento das Diretrizes Curriculares Nacionais para os Cursos de Graduação" (BRASIL, 2010). Nesse sentido, na reformulação de Projetos Pedagógicos de Cursos de Letras, a primeira determinação aos integrantes do Núcleo para sua elaboração é que estes estejam de acordo com as Diretrizes Curriculares para os Cursos de Letras e Diretrizes Curriculares Nacionais para a Formação de Professores. Em tais Diretrizes, a noção de competência como norteadora da organização curricular e dos projetos pedagógicos dos cursos ocupa espaço privilegiado.

Assim, neste artigo, objetivamos analisar a reação-resposta dos integrantes desse Núcleo aos preceitos legais de organização do currículo com base no conceito de competência, examinando, primeiramente, as Diretrizes Curriculares para os Cursos de Letras e para Formação de Professores e, posteriormente, o Projeto Pedagógico do Curso de Letras Português e Literatura ${ }^{2}$, reformulado pelos integrantes do NDE.

2 Selecionamos o Projeto Pedagógico do Curso de Letras Português e Literatura, tendo em vista que "Língua Portuguesa" e "Literatura" são áreas comuns aos demais cursos de Letras da instituição pesquisada, que tiveram os PPCs reformulados pelos professores do NDE. 
Com vista à consecução do objetivo, tomamos como base epistêmica e metodológica a Análise Dialógica do Discurso advinda dos estudos de Bakhtin e do Círculo. Consoante os preceitos bakhtinianos, trataremos da comunicação verbal, cujo exame será desenvolvido com o suporte dos conceitos de compreensão/resposta, discurso/ relações dialógicas e valoração. Partimos do pressuposto de que o Projeto Pedagógico de Curso (PPC) reformulado pelos sujeitos da pesquisa marca o posicionamento do grupo e dos professores dos cursos em tal fenômeno dialógico, estando nele presentes aquelas vozes que buscam a centralização, as diretrizes curriculares, ditando um modelo de formação do licenciando, e aquelas que relativizam essa centralização, apresentando, desse modo, um (in)tenso diálogo.

A pesquisa é relevante, uma vez que abrange movimentos e temas extremamente pertinentes na atualidade, como as discussões na academia em torno da reestruturação curricular de cursos nesse contexto em que a formação de professores tomou lugar nos discursos oficiais e as vozes das universidades buscam assentar seus valores no âmbito da qualidade do ensino. Condicionada a esses aspectos está também a relevância de apresentar estudos no campo da análise dialógica do discurso a partir de aspectos curriculares, com propósitos que revelem seu impacto nos resultados alcançados, enfocando, principalmente, a responsividade dos reestruturadores dos cursos de Letras aos discursos legais.

Na elaboração do artigo, inicialmente discorremos sobre o embasamento teóricometodológico que ancora a pesquisa. Em seguida, abordamos a noção de competência nos documentos oficiais que orientam as reformas curriculares nos cursos de Letras e Formação de Professores. A seção analítica se desdobra em resultados da análise dos discursos oficiais acerca das competências, enquanto princípio de organização curricular, e análise dos discursos dos sujeitos da pesquisa constantes no Projeto Pedagógico do Curso de Letras Português e Literatura, enfocando sua reação-resposta àqueles discursos. Após, apresentamos as considerações finais.

\section{Aspectos teórico-metodológicos}

À luz dos estudos de Bakhtin e do Círculo, neste trabalho, partimos da compreensão de que todo enunciado nasce e se desenvolve a partir da interação entre os sujeitos, dialogando com os enunciados já-ditos, seus precedentes e direcionando-se aos enunciados futuros dos quais se espera uma resposta. Nesse sentido, o enunciado se faz pela posição ativa dos sujeitos falantes no processo de comunicação, o que torna o papel do outro excepcional nesse processo. 
- Currículo por competências: (des)encontros entre os discursos oficial e pedagógico

Tal pensamento remete aos conceitos de compreensão e resposta (responsividade), que muito interessa ao percurso analítico deste trabalho. Para Bakhtin (2011b), a palavra do outro coloca diante do indivíduo a tarefa especial de compreendê-la. Nessa direção, o ouvinte, ao perceber e compreender o significado do discurso, passa a ocupar, em relação a ele, uma ativa posição responsiva que ocorre sempre concomitantemente ao ato discursivo do locutor, formando-se "ao longo de todo o processo de audição e compreensão desde o seu início, às vezes literalmente a partir da primeira palavra do falante" (BAKHTIN, 2011b, p. 271). Em outros termos, o ouvinte expressa sua posição de concordância ou discordância (total ou parcialmente) frente ao conteúdo do enunciado. Assim, "toda compreensão da fala viva, do enunciado vivo é de natureza ativamente responsiva [...] toda compreensão é prenhe de resposta, e nessa ou naquela forma a gera obrigatoriamente: o ouvinte se torna falante." (BAKHTIN, 2011b, p. 271).

Nessa ótica, a compreensão nasce no meio de um processo dialógico, já que o eu espera a resposta do outro e a alternância desses sujeitos coloca o ouvinte como falante, completando, desse modo, a interação discursiva. Para Bakhtin (2014, p. 90), a resposta "cria o terreno favorável à compreensão de maneira dinâmica e interessada. A compreensão amadurece apenas na resposta. A compreensão e a resposta estão fundidas dialeticamente e reciprocamente condicionadas, sendo impossível uma sem a outra".

Assim, não há compreensão sem uma antipalavra ${ }^{3}$, no dizer de Volóchinov (2017), isto é, sem resposta. E resposta na acepção bakhtiniana de posicionamento axiológico diante do enunciado do outro. Mesmo o silêncio constitui uma resposta. Nesse sentido, o sujeito discursivo só estará apto a responder se ele se posicionar, seja concordando, seja discordando, seja de modo indiferente. As respostas que provêm da atitude do interlocutor, esperadas pelo locutor, representam o reconhecimento do discurso, a compreensão de seu significado, além de conterem uma apreciação (posição valorativa) e a participação desse interlocutor. O locutor, por seu lado, também é um respondente ativo, dado que seus próprios enunciados estabelecem uma relação com outros anteriores aos seus, que servem de base para a construção de seus próprios enunciados, avaliados pelo interlocutor.

\footnotetext{
3 Utilizamos neste artigo a nova tradução de Marxismo e filosofia da linguagem: problemas fundamentais do método sociológico na ciência da linguagem (MFL), de Valentin Volóchinov, feita por Sheila Grillo e Ekaterina Vólkova Américo, realizada diretamente do original russo. Nessa nova versão, o termo "contrapalavra" da tradução anterior, utilizado há quatro décadas por pesquisadores brasileiros que se debruçam sobre o pensamento bakhtiniano, foi substituído por "antipalavra", opção adotada neste trabalho, conservando o sentido de resposta à palavra do outro.
} 
É sob esse entendimento que analisaremos os discursos-respostas dos professores do NDE, constantes no Projeto Pedagógico do Curso de Letras Português e Literatura. A partir da forma como esses professores reelaboram os enunciados oficiais que normatizam e regulam os cursos de Letras, criticando, questionando, concordando ou não com o discurso das competências, enquanto princípio de organização curricular, consignado em tais documentos, buscaremos apreender, em seus discursos, os valores que defendem para a formação do licenciando em Letras.

Considerando que a natureza do enunciado é dialógica, a relação discursoresposta dos professores que compõem o NDE dos cursos de Letras estudados neste trabalho será considerada na produção dos sentidos, visto que somente no diálogo eles são gerados. Desse modo, os sentidos aflorarão a partir do estabelecimento das relações dialógicas entre os discursos dos integrantes do NDE presentes no Projeto Pedagógico de Curso e Discursos oficiais da educação que orientam a construção desse documento, uma vez que "os enunciados não são indiferentes entre si nem se bastam cada um a si mesmos; uns conhecem os outros e se refletem mutuamente uns nos outros" (BAKHTIN, 2011b, p. 297).

Para que as relações dialógicas aconteçam, é necessário que haja, apenas, uma convergência ou uma confrontação de sentidos entre dois enunciados diferentes. As relações dialógicas que a obra bakhtiniana formata não se reduzem a relações lógica, linguística ou mecânica, mas pressupõem a linguagem, pensada no grande diálogo da comunicação discursiva. Desse modo, elas não podem ser separadas do campo discursivo, dado que o verdadeiro campo da linguagem é constituído pela comunicação dialógica. É somente nesse âmbito que é possível estabelecer relações de sentido com a palavra do outro, as quais acarretam atitudes responsivas oriundas do encontro de posições axiológicas.

Essa visão está associada a outro prisma da análise dialógica do discurso de fundamental importância para o estudo aqui proposto que é considerar o enunciado como instância da expressão do posicionamento valorativo do locutor frente ao objeto de seu discurso. Conforme teoriza Bakhtin (2011a, p. 173-174, grifo do autor):

O eu e o outro são as categorias axiológicas basilares, que pela primeira vez tornam possível qualquer juízo de valor efetivo, e um momento desse juízo, ou melhor, a diretriz axiológica da consciência não ocorre só no ato na verdadeira acepção do termo, mas em cada vivenciamento e até na sensação mais simples: viver significa ocupar uma posição axiológica em cada momento da vida, significa firmar-se axiologicamente. 
- Currículo por competências: (des)encontros entre os discursos oficial e pedagógico

Isso significa que a interação entre os interlocutores é formada por uma ênfase valorativa; consequentemente, as ênfases valorativas são ideológicas e sociais e estão ligadas à composição de um auditório social, pois o falante interage discursivamente a partir do horizonte axiológico (valorativo) que tem de uma época e de um grupo social específico.

Logo, os Pareceres que instituem as Diretrizes Curriculares para os Cursos de Letras e para Formação de Professores, assim como o Projeto Pedagógico do Curso de Letras Português e Literatura, estudados neste trabalho, estão inerentemente associados às instâncias institucionais em que foram produzidos e, por isso, refletem e refratam seus valores ideológicos, remetendo a uma posição axiológica. Tais enunciados são acompanhados por uma ênfase valorativa determinada, uma vez que, como explica Volóchinov (2017, p. 233), "sem uma ênfase valorativa, não há palavra". E "palavra", aqui, é tomada na acepção de enunciado, como signo ideológico no plano do uso da língua, produzindo sentidos.

Desse modo, as palavras, enquanto signos ideológicos, só ganham sentido a partir da valoração individual e da valoração social, estando aquela intrinsecamente imbricada com as valorações sociais circundantes. Isso acontece porque a palavra é parte de uma realidade social. Nesse aspecto, a avaliação social é elemento primordial do processo de refração de sentidos no signo ideológico.

Essas perspectivas se constituem em referenciais importantes para o estudo que nos propusemos a realizar, cujo corpus é formado por enunciados de duas esferas de produção de saberes: Estado (Pareceres exarados pelo Conselho Nacional de Educação que fundamentam as Diretrizes Curriculares, emitidas em 2001 e 2015, voltadas para os Cursos de Letras e de formação de professores) e universidade (Projeto Pedagógico do Curso de Letras Português e Literatura, reestruturado pelos integrantes do NDE).

Para análise dos dados, partimos da ordem metodológica sociológica de análise da linguagem, proposta por Volóchinov (2017, p. 220), que apresenta as seguintes etapas para o estudo da língua:

1) formas e tipos de interação discursiva em sua relação com as condições concretas;

2) formas dos enunciados ou discursos verbais singulares em relação estreita com a interação da qual são parte, isto é, os gêneros dos discursos verbais determinados pela interação discursiva na vida e na criação ideológica;

3) partindo disso, revisão das formas da língua em sua concepção linguística habitual. 
Assim, seguindo essas orientações, para a análise do caráter de responsividade dos integrantes do NDE dos cursos de Letras estudados aos discursos das competências que atravessam os documentos oficiais, é indispensável, antes, estudarmos tais enunciados. Nesse sentido, após abordarmos a noção de competência enquanto princípio de organização curricular, analisaremos, num primeiro momento, os Pareceres CNE/CES n. 492/2001 e Parecer CNE/CP n. 009/2001 que fundamentam, respectivamente, as Diretrizes Curriculares Nacionais para os Cursos de Letras (DCL) e as Diretrizes Curriculares Nacionais para a Formação de Professores (DCF), com objetivo de apreender os sentidos relacionados ao conceito de competência. Posteriormente, analisaremos o Projeto Pedagógico do Curso de Letras Português e Literatura, focalizando os discursos-respostas dos sujeitos da pesquisa ao conceito de competência como princípio organizador do currículo, defendido nas referidas Diretrizes.

\section{A noção de competência enquanto princípio de organização curricular}

De acordo com Bakhtin (2011b, p. 294), "em cada época, em cada círculo social [...] sempre existem essas ou aquelas ideias determinantes dos 'senhores do pensamento' de uma época [...]". Tais ideias encontram seu auge e seu declínio a partir da maneira como são valoradas pelos sujeitos que constituem a esfera de comunicação social.

No contexto de produção das Diretrizes Curriculares Nacionais para os Cursos de Letras (DCL) e Diretrizes Curriculares Nacionais para Formação de professores da Educação Básica (DCF), publicadas em 2001, uma das "ideias determinantes" que se destacaram como eixo norteador da organização curricular é a do ensino por competências, que toma como ponto de partida o discurso da necessidade de melhoria da qualidade educacional. Por essa perspectiva, a competência se torna base para a formação comum dos licenciandos e para inserção de uma nova concepção de ensino e de organização curricular.

A palavra "competência", na história do currículo, está relacionada à atuação em circunstâncias concretas ou à experiência profissional. Para ela se realizar, necessita de ação, ou seja, de uma atividade prática, de situações concretas e contextualizadas. Esse sentido é perceptível no Parecer CNE/CP n. 009/2001 que estabelece as DCF. Conforme o Parecer, competência é a capacidade de mobilizar e colocar em ação conhecimentos indispensáveis para o desempenho das atividades demandadas pela característica do trabalho: 
- Currículo por competências: (des)encontros entre os discursos oficial e pedagógico

As competências tratam sempre de alguma forma de atuação, só existem 'em situação' e, portanto, não podem ser aprendidas apenas no plano teórico nem no estritamente prático. A aprendizagem por competências permite a articulação entre teoria e prática e supera a tradicional dicotomia entre essas duas dimensões, definindo-se pela capacidade de mobilizar múltiplos recursos numa mesma situação, entre os quais os conhecimentos adquiridos na reflexão sobre as questões pedagógicas e aqueles construídos na vida profissional e pessoal, para responder às diferentes demandas das situações de trabalho. (BRASIL, 2001b, p. 30, grifo nosso).

Tal definição dialoga com o pensamento de Perrenoud (2000, p. 13), que define competência como sendo a "capacidade de mobilizar diversos recursos cognitivos para enfrentar um tipo de situação", explicando que a definição compreende os seguintes aspectos:

1. As competências não são elas mesmas saberes, savoir-faire ou atitudes, mas mobilizam, integram e orquestram tais recursos; 2 . Essa mobilização só é pertinente em situação, sendo cada situação singular, mesmo que se possa tratá-la em analogia com outra, já encontrada; 3. O exercício da competência passa por operações mentais complexas, subentendidas por esquemas de pensamento [...]; 4. As competências profissionais constroem-se, em formação, mas também ao sabor da navegação diária de um professor [...] (PERRENOUD, 2000, p. 13-14, grifo do autor).

As perspectivas apresentadas no excerto apontam para a compreensão da competência como a incorporação e a mobilização de saberes para a ação. Em outras palavras, a competência significa, sobretudo, a capacidade de mobilizar recursos cognitivos para atuar em certas circunstâncias, diferenciando-se dos saberes, do saber fazer e das atitudes, uma vez que ela é a mobilização de recursos relativos às situações enfrentadas pelo sujeito, de modo singular e único.

A formação, nessa ótica, sinaliza para o perfil profissional de um educador cumpridor de tarefas circunstanciais. Nesse sentido, os professores seriam formados para aprender aquilo que é de utilidade imediata, o que torna a sua formação superficial e pragmática, voltada para o mundo do trabalho. As DCL e DCF, assim, têm sofrido várias críticas devido ao seu perfil instrumental-tecnicista, que supervaloriza o pragmatismo praticista, embasado no conceito de competência. 
Respondendo a anseio de educadores (FREITAS, 2015), em 2015, o Conselho Nacional de Educação (CNE) revogou a Resolução CNE/CP n. 1/2002 que institui as DCF, fundamentadas no conceito de competências, aprovando as novas Diretrizes Curriculares Nacionais para a Formação Inicial e Continuada dos Profissionais do Magistério da Educação Básica (NDCF), estabelecidas pelo Parecer CNE/CP n. 002/2015 e instituídas pela Resolução CNE/CP 002/2015.

Nunes (2017), em estudo realizado nos Pareceres CNE/CP n. 002/2015 e CNE/CP 009/2001, a partir da perspectiva dialógica, constatou que os enunciadores do Parecer de 2015 não pronunciam o termo "competência" no texto, substituindo, inclusive, a expressão "competências e habilidades" (largamente utilizada nos discursos oficiais) por "informações e habilidades", "conhecimentos e habilidades". Não obstante, analisando vozes presentes no referido Parecer, o autor observou que tais enunciadores respondem favoravelmente ao discurso da formação para as competências, ao prescreverem que parte da formação do professor deve ocorrer em diferentes espaços escolares, enfatizando, desse modo, o conhecimento construído "na" e "pela" experiência, "em situação". Ademais, constata-se, no documento, a reenunciação de vozes presentes no conjunto das competências definidas no Parecer CNE/CP n. 009/2001, assim como a assimilação da perspectiva de formação veiculada nos discursos oficiais que defendem o ensino por competência.

Assim, se por um lado os enunciadores tentam negar vinculação com o modelo de formação baseado em competências, apagando e substituindo termos a ele relacionados, por outro, seus discursos apresentam grande convergência com os discursos das DCL e DCF, que tomaram o conceito de competências como nuclear para a formação de professores.

Cabe destacar que, nas NDCF, os princípios que fundamentam o conceito de competência estão presentes, mas este não é tomado como nuclear na orientação dos cursos de formação de professores. Nas DCF (revogadas) e nas DCL (em vigência), ao contrário, a concepção de competência é adotada como norteadora da proposta pedagógica.

Nessa perspectiva, na seção seguinte, analisaremos os Pareceres CNE/CES n. 492/2001 e CNE/CP n. 009/2001, que fundamentam, respectivamente, as DCL e as DCF. A análise desses enunciados se faz necessária, para que possamos apreender, no Projeto Pedagógico reformulado pelos professores que integram o NDE, quais diretrizes tecem seus discursos ${ }^{4}$.

4 Destacamos que os professores do NDE começaram o trabalho de reformulação dos PPCs, oficialmente, em janeiro de 2014. A coleta de dados iniciou-se nesse mesmo ano, encerrando-se em 2015, ano em que as NDCF foram publicadas, revogando-se as DCF. 
- Currículo por competências: (des)encontros entre os discursos oficial e pedagógico

\section{Sentidos de Competência nas DCL e DCF}

Nesta parte do trabalho, analisaremos os Pareceres CNE/CES n. 492/2001 e CNE/ CP n. 9/2001 que estabelecem, respectivamente, as Diretrizes Curriculares para os Cursos de Letras (DCL) e as Diretrizes Curriculares para Formação de Professores (DCF), a partir do estabelecimento de relações dialógicas, observando, com base no conceito bakhtiniano de valoração, como eles dialogam entre si para produzir sentidos quanto ao princípio das competências como organizador do currículo. Em consonância com o pensamento bakhtiniano, consideramos que os discursos dos dois Pareceres se entrelaçam com interações complexas, como as estabelecidas com as estruturas sociais e acontecimentos de cunho político-educacional do contexto em que foram produzidos.

No texto do Parecer CNE/CES n. 492/2001 que apresenta e fundamenta as DCL, o termo competência é usado recorrentemente, aparecendo nove vezes, considerandose a introdução e os cinco itens de diretrizes curriculares. A introdução traz o seguinte posicionamento:

Por sua natureza teórico-prática, essencialmente orgânica, o currículo deve ser constituído tanto pelo conjunto de conhecimentos, competências e habilidades, como pelos objetivos que busca alcançar.

Assim, define-se currículo como todo e qualquer conjunto de atividades acadêmicas que integralizam um curso. Essa definição introduz o conceito de atividade acadêmica curricular - aquela considerada relevante para que $o$ estudante adquira competências e habilidades necessárias a sua formação e que possa seravaliada interna externamente como processo contínuo e transformador, conceito que não exclui as disciplinas convencionais. (BRASIL, 2001a, p. 29, grifo nosso).

Conforme o excerto, a adoção das competências no currículo objetiva que se organize o processo de ensino em função delas, exigindo uma lógica para o curso que priorize atividades consideradas relevantes "para que o estudante adquira competências e habilidades necessárias à sua formação". Percebe-se também que no Parecer o conceito de competência está intimamente relacionado à avaliação de resultados e sinaliza, a um só tempo, para o controle da formação e do exercício da profissão.

A afirmação de que o conceito de "atividade acadêmica curricular" não "exclui as disciplinas convencionais" opera como uma antecipação de respostas a críticas de que as DCL estariam negando a importância das disciplinas na formação inicial do professor. 
Desse modo, busca-se rebater a alegação de que as disciplinas convencionais não seriam necessárias ao processo formativo do licenciando em Letras.

Ainda no Parecer que fundamenta as DCL, no item 2 - "competências e habilidades", lemos:

O graduado em Letras, tanto em língua materna quanto em língua estrangeira clássica ou moderna, nas modalidades de bacharelado e de licenciatura, deverá ser identificado por múltiplas competências e habilidades adquiridas durante sua formação acadêmica convencional, teórica e prática, ou fora dela.

[...] o curso de Letras deve contribuir para o desenvolvimento das seguintes competências e habilidades:

- domínio do uso da língua portuguesa ou de uma língua estrangeira, nas suas manifestações oral e escrita, em termos de recepção e produção de textos;

- reflexão analítica e crítica sobre a linguagem como fenômeno psicológico, educacional, social, histórico, cultural, político e ideológico;

- visão crítica das perspectivas teóricas adotadas nas investigações linguísticas e literárias, que fundamentam sua formação profissional;

- preparação profissional atualizada, de acordo com a dinâmica do mercado de trabalho;

- percepção de diferentes contextos interculturais;

- utilização dos recursos da informática;

- domínio dos conteúdos básicos que são objeto dos processos de ensino e aprendizagem no ensino fundamental e médio;

- domínio dos métodos e técnicas pedagógicas. (BRASIL, 2001a, p. 30, grifo nosso).

No Parecer CNE/CES n. 492/200, que fundamenta as DCL, percebemos, em sua globalidade, a existência de uma luta ideológica em que prevalece a perspectiva centrada no desenvolvimento de competências, cujo modelo de formação supervaloriza o pragmatismo praticista. Todavia, no excerto em análise, extraído do item "competências e habilidades", percebemos que o discurso é interpelado por outros discursos provenientes de uma concepção que valoriza a reflexão teórica do processo formativo. Essa valoração 
- Currículo por competências: (des)encontros entre os discursos oficial e pedagógico

se manifesta em expressões como "domínio do uso da língua", "reflexão analítica e crítica sobre a linguagem", "visão crítica das perspectivas teóricas" e "domínio dos conteúdos básicos". Observa-se, desse modo, que tais diretrizes demonstram ser marcadas também pelo discurso da racionalidade técnica, por valorizarem um conjunto de saberes caracteristicamente teóricos.

Ouvem-se, então, no excerto, pelo menos duas vozes, cujo processo de produção de significados é carregado de tensões: uma que defende a emissão de um juízo prático e outra que prioriza o domínio de teorias. As DCL são, assim, consoante o pensamento bakhtiniano, um espaço de luta entre as diferentes vozes e suas perspectivas axiológicas.

Quanto às DCF, no Parecer CNE/CP n. 009/2001 que as fundamenta, a concepção de competência é apresentada como um "paradigma curricular novo" (BRASIL, 2001b, p. 8), sendo considerada nuclear tanto para organização do currículo quanto para a organização do curso como um todo:

Conceber e organizar um curso de formação de professores implica: a) definir o conjunto de competências necessárias à atuação profissional; b) tomá-las como norteadoras tanto da proposta pedagógica, em especial do currículo e da avaliação, quanto da organização institucional e da gestão da escola de formação. (BRASIL, 2001b, p. 35-36).

Com base na concepção de competência, há, no documento, a definição de um conjunto de "competências a serem desenvolvidas na formação da educação básica", a saber: (i) competências referentes ao comprometimento com os valores inspiradores da sociedade democrática; (ii) competências referentes à compreensão do papel social da escola; (iii) competências referentes ao domínio dos conteúdos a serem socializados, de seus significados em diferentes contextos e de sua articulação interdisciplinar; (iv) competências referentes ao domínio do conhecimento pedagógico; (v) competências referentes ao conhecimento de processos de investigação que possibilitem o aperfeiçoamento da prática pedagógica; (vi) competências referentes ao gerenciamento do próprio desenvolvimento profissional.

Enquanto nas DCL há o destaque para o desenvolvimento de competências e habilidades específicas do Curso de Letras, nas DCF, as competências elencadas figuram como gerais para todos os cursos de licenciatura. Nessa direção, a partir do estabelecimento de relações dialógicas entre o Parecer CNE/CP n. 009/2001 e o Parecer CNE/CES n. 492/2001, buscaremos verificar como ocorre o diálogo entre as vozes que perpassam os enunciados, partindo sempre do conjunto de competências definidas no Parecer que fundamenta as Diretrizes para Formação de Professores. 
Nas "competências referentes ao comprometimento com os valores inspiradores da sociedade democrática" (BRASIL, 2001b), o Parecer que fundamenta as DCF aborda aquelas voltadas para o trabalho e para a cidadania, enfatizando os valores morais e éticos em que se fundamenta a sociedade. No que tange a essa abordagem, as DCL apoiam-se em um vago aceno à "percepção de diferentes contextos interculturais" (grifo nosso). No entanto, quanto à diversidade e à multiculturalidade, tanto nas DCF quanto nas DCL, a diferença é entendida como resultado ("reconhecer e respeitar a diversidade", nas DCF, e "percepção de diferentes contextos interculturais", nas DCL) e não como um processo resultante do uso da linguagem no âmbito das relações sociais (GONDIN; FERNANDES, 2011). Nesse aspecto, pode-se observar uma relação dialógica de consonância entre os discursos das duas diretrizes.

As "competências referentes à compreensão do papel social da escola" (BRASIL, 2001b, p. 41-42) são voltadas para o contexto educacional, envolvendo ações nos diferentes espaços escolares, como "participar coletiva e cooperativamente da elaboração, gestão, desenvolvimento e avaliação do projeto educativo e curricular da escola". As competências elencadas ratificam a ideia defendida no Parecer que fundamenta as DCF de que o preparo do futuro professor deve envolver ações nos diferentes espaços escolares. Nas DCL, no item que trata das competências, há silenciamento acerca dessa questão.

Quanto às "competências referentes ao domínio dos conteúdos a serem socializados, de seus significados em diferentes contextos e de sua articulação interdisciplinar" (BRASIL, 2001b, p. 42-43), estas abordam a necessidade de o professor "conhecer e dominar os conteúdos básicos relacionados às áreas/disciplinas de conhecimento que serão objeto da atividade docente". Tal discurso dialoga com as DCL, que esperam do profissional da área de Letras "domínio dos conteúdos básicos que são objeto dos processos de ensino e aprendizagem no ensino fundamental e médio". Nessa ótica, entende-se, conforme as duas Diretrizes, que o processo formativo deve ter como referência, principalmente, o nível de escolarização no qual o futuro professor trabalhará.

As "competências referentes ao domínio do conhecimento pedagógico" (BRASIL, 2001b, p. 43), como o nome anuncia, estão voltadas para as questões pedagógicas, relacionadas às formas de ensinar e aos modos de o professor lidar com os alunos. Pesquisas de estudiosos como Gatti e Nunes (2009) e Libâneo (2010a, 2010b, 2013) explicam que um dos nós da formação docente são as dificuldades dos professores em incorporar e articular na sua prática pedagógica dois quesitos essenciais no desempenho de suas funções: o "domínio dos conteúdos a serem socializados" e o "domínio do conhecimento pedagógico", ou seja, das habilidades para ensinar tais conteúdos. As DCL também fazem referência a essa questão, mas a abordam de modo restrito, orientando que o curso de 
- Currículo por competências: (des)encontros entre os discursos oficial e pedagógico

Letras deve contribuir para o desenvolvimento do "domínio dos métodos e técnicas pedagógicas que permitam a transposição dos conhecimentos para os diferentes níveis de ensino".

Nos itens elencados das "competências referentes ao conhecimento de processos de investigação que possibilitem o aperfeiçoamento da prática pedagógica" (BRASIL, 2001b, p. 43-44), constatamos um discurso com forte ênfase na pesquisa sobre a prática docente, com a preocupação de que o professor desenvolva uma postura investigativa sobre a sua área de atuação e que aprenda a usar procedimentos de pesquisa como instrumentos de trabalho.

Essas competências estão alinhadas à ideia de pesquisa ligada diretamente à prática, defendida no próprio Parecer que fundamenta as DCF: "a atuação prática possui uma dimensão investigativa e constitui uma forma não de simples reprodução, mas de criação ou, pelo menos, de recriação do conhecimento" (BRASIL, 2001b, p. 24). O discurso do Parecer encontra suporte na premissa de que o saber docente e a prática são elementos essenciais para o processo de investigação e que a pesquisa do professor não precisa seguir a mesma orientação metodológica da pesquisa científica acadêmica, por estar relacionada a diálogos ligados a ações de ensino-aprendizagem que vão sendo construídas no contexto escolar, não se caracterizando, desse modo, como teorias explicativas de algo (DINIZ-PEREIRA; LACERDA, 2009). Cabe destacar, porém, que essa forma de conceber a pesquisa como uma dimensão prática, instrumental, associada às necessidades advindas da prática cotidiana e à resolução de problemas, pode comprometer a formação dos professores. No que tange às DCL, no item "competências e habilidades", não há menção à pesquisa.

Nas "competências referentes ao gerenciamento do próprio desenvolvimento profissional" (BRASIL, 2001b, p. 44) definidas nas DCF, percebemos um discurso de supervalorização do caráter individualizado do conhecimento, como o próprio nome evidencia, estimulando o professor, entre outras ações, a "elaborar e desenvolver projetos pessoais de estudo e trabalho". Embasa tais competências a ideia de que o sujeito competente é aquele capaz de mobilizar, de executar, de maneira eficaz, as diferentes funções de um sistema, envolvendo uma diversidade considerável de recursos. Sob essa perspectiva, ele será capaz de gerenciar o seu próprio desenvolvimento profissional.

A posição defendida nessas competências acaba por eximir o governo e a sociedade da responsabilidade de formar continuamente o professor, deixando essa tarefa a cargo do sujeito, que será responsável pelo seu (in)sucesso. Nesse sentido, há um deslocamento da responsabilidade social para o plano individual (FRIGOTTO, 1998), 
cabendo ao docente mobilizar competências diversas diante das exigências de uma sociedade em constante transformação. As DCL não abordam diretamente a competência referente ao gerenciamento do próprio desenvolvimento profissional, mas o próprio conceito de competência adotado em seu discurso pressupõe um constructo teórico de caráter individualista.

Faz-se mister registrar que, tanto no Parecer que fundamenta as DCL quanto no que fundamenta as DCF, os conteúdos são vistos como meio e suporte para a construção de competências, como podemos observar nos excertos abaixo:

De forma integrada aos conteúdos caracterizadores básicos do curso de Letras, devem estar os conteúdos caracterizadores de formação profissional em Letras. Estes devem ser entendidos como toda e qualquer atividade acadêmica que constitua o processo de aquisição de competências e habilidades necessárias ao exercício da profissão. (BRASIL, 2001a, p. 31, grifo nosso).

Os conteúdos definidos para um currículo de formação profissional e o tratamento que a eles deve ser dado assumem papel central, uma vez que é basicamente na aprendizagem de conteúdos que se dá a construção e o desenvolvimento de competências. (BRASIL, 2001b, p. 33, grifo nosso).

De tudo que discutimos até aqui, podemos dizer que os discursos presentes no Parecer CNE/CES n. 492/2001 mantêm relação dialógica de convergência com o discurso da formação para as competências, professado no Parecer CNE/CP n. 009/2001, marcando o posicionamento valorativo dos enunciadores em relação ao tema. Em vários momentos, o discurso de tais enunciadores se entrelaça com o discurso do Parecer CNE/CP n. 009/2001, fundindo-se com algumas vozes nele presentes, completando ou silenciando outras, atualizando, desse modo, sentidos sobre a formação docente.

Podemos inferir que os sentidos atribuídos à competência, no bojo das relações dialógicas estabelecidas entre os Pareceres, remetem à capacidade real do sujeito para atingir um objetivo ou um resultado num dado contexto. No sentido utilizado nos Pareceres, competências são aquisições, aprendizados construídos ao longo da formação. Assim, os documentos apresentam uma lista de resultados esperados, de desempenhos considerados satisfatórios em uma dada situação, em consequência desse processo de formação. O Parecer que fundamenta as DCF ainda orienta que as competências "devem ser complementadas e contextualizadas pelas competências específicas próprias de cada etapa e de cada área do conhecimento a ser contemplada na formação" (BRASIL, 2001b, p. 41). Portanto, ao currículo por competências devem estar associados desempenhos que demonstrem a sua aquisição. 
- Currículo por competências: (des)encontros entre os discursos oficial e pedagógico

Passemos, na seção seguinte, à análise do Projeto Pedagógico do Curso de Letras Português e Literatura, com objetivo apreender o diálogo existente entre esse documento e os Pareceres examinados.

\section{Diretrizes Curriculares e Projeto Pedagógico de Curso: os discursos sobre os princípios da formação por competência em confronto}

Nesta seção, a partir do estabelecimento de relações dialógicas entre o Projeto Pedagógico do Curso de Letras Português e Literatura e os Pareceres CNE/CES n. 492/2001 e CNE/CP n. 009/2001, buscaremos verificar como os discursos das competências materializados nesses Pareceres são compreendidos e implementados pelos integrantes do NDE no PPC, buscando desvelar a reação-resposta desses sujeitos aos dispositivos legais. Conforme Volóchinov (2017), compreender é apresentar à palavra do locutor uma antipalavra. Desse modo, "a significação não está na palavra, nem na alma do falante, nem na alma do ouvinte. A significação é um efeito da interação entre o falante e o ouvinte no material de um dado conjunto sonoro" (VOLÓCHINOV, 2017, p. 232233, grifo do autor). Assim, para a análise do Projeto Pedagógico, serão fundamentais os conceitos de compreensão/resposta, discurso e relações dialógicas, que implicam relações de convergência ou divergência, de harmonia ou de conflitos, possibilitando a apreensão dos sentidos da formação docente, a partir dos princípios presentes na arena discursiva do documento.

O Projeto Pedagógico de Curso constitui um gênero discursivo com uma configuração que o tipifica e o diferencia de outros gêneros da esfera acadêmicouniversitária. Conforme o pensamento bakhtiniano, é na dialogia possível da prática que estão inseridos os gêneros do discurso ou os diversos tipos de enunciados, relativamente estáveis do ponto de vista temático, composicional e estilístico, caracterizados pelos contextos nos quais são utilizados. O Projeto Pedagógico de Curso é produção institucionalizada, de circulação social pública, constituído por enunciados concretos escritos, com informações acerca da concepção e da estrutura do curso e seus elementos regulares internos, sendo considerado o norteador das atividades desenvolvidas no processo de formação do estudante. Esse instrumento de relação social reflete a posição axiológica de seus autores no momento de sua elaboração, funcionando como o centro organizador das atividades dos professores do quadro do curso ${ }^{5}$.

\footnotetext{
5 Para a análise do Projeto Pedagógico do Curso de Letras Português e Literatura, levantamos dados da "Introdução", das seções "Organização didático-pedagógica", "Operacionalização do curso", "Gestão do curso" e "Ementário". As outras partes do documento, por tratarem de informações de ordem estrutural/ organizacional, não foram focalizadas. Na parte introdutória do PPC, constam o "Histórico do curso" e
} 
$\mathrm{Na}$ introdução do Projeto Pedagógico do Curso de Letras Português e Literatura (PPCP), há a informação de que o curso "se preocupa em oportunizar ao acadêmico a participação em atividades que the proporcionem o crescimento como profissional e cidadão autônomo e responsável, valorizando seus interesses e suas necessidades". Há ainda o esclarecimento de que busca "desenvolver habilidades e competências necessárias às realidades, com vista à inserção do acadêmico na sociedade e ao exercício da cidadania e da profissão" (PPCP, 2015, p. 7, grifo nosso).

Observamos que a introdução do PPCP é uma resposta positiva às deliberações das Diretrizes Curriculares Nacionais para os Cursos de Letras (DCL) e Diretrizes Curriculares Nacionais para Formação de Professores da Educação Básica (DCF), ao esclarecer que o curso tem como propósito possibilitar ao licenciando o desenvolvimento de competências e habilidades, conforme preconizam tais documentos oficiais, com vista a preparar e adequar os professores em formação para uma nova ordem que se define pelas diferentes competências e habilidades com que devem enfrentar os desafios profissionais e sociais. Nesse aspecto, desenvolver "competências necessárias às realidades" significa desenvolver no licenciando a capacidade de mobilizar conhecimentos e habilidades para resolver os problemas da vida cotidiana. Para sustentar o posicionamento manifesto, os enunciadores trazem para o texto as vozes das Diretrizes para os cursos de Letras ao tratarem da Concepção do Curso:

De acordo com as diretrizes, os profissionais em Letras devem "ter domínio do uso da língua ou das línguas que sejam objeto de seus estudos, em termos de sua estrutura, funcionamento e manifestações culturais". Deles se esperam múltiplas competências e habilidades para atuarem como 'professores, pesquisadores, críticos literários, tradutores, intérpretes, revisores de textos, roteiristas, secretários, assessores culturais, entre outras atividades'. Vale lembrar que o processo articulatório entre habilidades e competências no curso de Letras pressupõe o desenvolvimento de atividades de caráter prático durante o período de integralização do curso. (PPCP, 2015, p. 21, grifo nosso).

No excerto, mostrando-se favorável à noção de competência, os enunciadores, professores que integram o NDE, destacam que "o processo articulatório entre habilidades

\footnotetext{
a "Justificativa para reelaboração do PPC". A seção "Organização didático-pedagógica" está dividida em "Contexto Educacional, Profissional, Laboral" e "Concepção do curso". O primeiro item dessa seção é a explicitação das demandas efetivas que justificam a oferta do curso. O segundo é a apresentação do que é o curso no contexto social e institucional. Na seção "Operacionalização do curso", há a explicação sobre como o curso funciona. Em "Ementários", estão as ementas das disciplinas e em "Apêndice", os regulamentos do Estágio Supervisionado e das Atividades Complementares.
} 
- Currículo por competências: (des)encontros entre os discursos oficial e pedagógico

e competências no curso de Letras pressupõe o desenvolvimento de atividades de caráter prático", explicitando, desse modo, uma concepção alinhada àquela propugnada nas DCL e DCF, sobretudo nessas últimas, em que a noção presente é de que a competência para se realizar necessita de ação, ou seja, de uma atividade prática, de situações concretas e contextualizadas. Ressaltam também que o curso "visa a desenvolver uma série de competências e habilidades, embasadas numa tradição de educação humanista com uma concepção teórico-crítico-ideológica" (PPCP, 2015, p. 24).

Em resposta ao princípio regulamentado constante do Parecer CNE/CP n. 009/2001, que fundamenta as DCL, de considerar a competência como concepção nuclear na orientação do curso, bem como as orientações das DCF, os enunciadores do PPCP assim se posicionam no item "Perfil do Egresso e Objetivos do Curso":

Trata-se, portanto, de uma urgente ressignificação do ensino de Língua Portuguesa: é preciso formar professores capazes de (re)construir suas concepções sobre língua, linguagem, gramática, texto, produção escrita e oral, a fim de que tenham a prática docente adequada à proposta de ensino de língua que se pretende mais reflexivo, mais contextualizado e menos fragmentado; que desenvolva no aluno as competências sociointerativas, linguísticas e reflexivas, como sugerem os documentos oficiais.

Tais pressupostos envolvem, segundo as diretrizes, o desenvolvimento das seguintes competências e habilidades básicas:

- domínio do uso da língua portuguesa ou de uma língua estrangeira, nas suas manifestações oral e escrita, em termos de recepção e produção de textos;

- reflexão analítica e crítica sobre a linguagem como fenômeno psicológico, educacional, social, histórico, cultural, político e ideológico;

- visão crítica das perspectivas teóricas adotadas nas investigações linguísticas e literárias, que fundamentam sua formação profissional;

- preparação profissional atualizada, de acordo com a dinâmica do mercado de trabalho;

- percepção de diferentes contextos interculturais;

- utilização dos recursos da informática; 
- domínio dos conteúdos básicos que são objeto dos processos de ensino e aprendizagem no ensino fundamental e médio;

- domínio dos métodos e técnicas pedagógicas que permitam a transposição dos conhecimentos para os diferentes níveis de ensino.

Assim, o Curso Letras Língua Portuguesa/Literatura visa a:

- aperfeiçoar a competência de comunicação escrita e oral na Língua Portuguesa;

- oferecer ao aluno subsídios para a leitura, análise e crítica de textos literários e não literários;

- promover a compreensão do funcionamento da Língua Portuguesa, seus usos e variações;

- capacitar o aluno a identificar questões de análises relativas tanto à forma linguística e literária como aos seus conteúdos. (PPCP, 2015, p. 31-32).

É interessante observar, no excerto, que os enunciadores exibiram as mesmas competências elencadas no Parecer CNE/CES 492/2001, reportando o discurso do documento ("segundo as diretrizes"), mas não apresentaram nenhuma reflexão sobre elas. Utilizando-se do operador argumentativo "assim", após apresentar ipsis litteris cada uma das competências do documento, passam para os objetivos do curso, como se concordassem com aquela listagem, mas sem apresentar sua apreciação explícita sobre a questão, nem mesmo expondo a constituição de outras competências requeridas do futuro professor de língua materna no curso. Uma rápida leitura poderia nos levar a entender que a autonomia universitária se encontra comprometida com essa posição dos autores por associarem o documento oficial ao próprio texto sem manifestação de suas antipalavras.

Todavia, tal posicionamento, instaurado no discurso do PPCP, promove sentidos que, ao contrário, entram em tensão com o discurso das DCL. Entendemos que os autores mencionaram as competências porque as Diretrizes assim exigem, apresentando uma aparente concordância com o discurso das DCL. Mas a forma adotada para atender ao dispositivo legal, em que os enunciadores não se envolvem com o discurso oficial, estabelece um efeito de sentido, evidenciando, na verdade, um não comprometimento de tomá-las, quando da construção da proposta curricular, como referencial para sua organização. 
- Currículo por competências: (des)encontros entre os discursos oficial e pedagógico

Essa percepção se confirma quando analisamos o documento como um todo. O exame revela que a concepção de competência não foi adotada como base da organização curricular, objetivando a sua sintonia com a "nova organização do mundo do trabalho", conforme as orientações das DCL e DCF. Constata-se que a matriz curricular parte de uma listagem de disciplinas obrigatórias e específicas e respectivas cargas horárias, sem dar mostras de que a competência tenha sido tomada como concepção nuclear da organização do currículo. Conforme Santos (2011, p. 91-92), a construção de uma proposta curricular utilizando o princípio das competências não pode estar "presa a um ensino por conteúdos, fragmentado, pouco flexível, pautado no encadeamento de disciplinas e desprovido do dinamismo necessário para atender às frequentes demandas por mudanças do mundo atual". O autor destaca ainda que:

O ponto de partida para a estruturação curricular devem ser as DCNs, que estabelecem as competências e habilidades a serem enfatizadas na graduação, cabendo a cada instituição definir sua matriz de competências, estabelecer e descrever claramente sua composição, estratificar seu desenvolvimento ao longo do currículo e elaborar um sistema de avaliação devidamente ajustado aos objetivos educacionais estabelecidos. (SANTOS, 2011, p. 92).

No PPCP, observamos que, apesar de os sujeitos enunciativos mencionarem o rol de competências extraídas do Parecer CNE/CES n. 492/2001, que fundamenta as DCL, os critérios de organização curricular adotados priorizaram a descrição de uma matriz nos moldes do ensino por conteúdos, sem fazer constar as competências reportadas das DCL. Também não são as competências que orientam a seleção e o ordenamento de conteúdos, nem a definição de tempos e espaços curriculares do curso.

No que diz respeito às DCF, as competências listadas nos seis grupos de demandas para a formação docente, como analisamos na seção anterior, estão relacionadas à capacidade de ação frente a uma determinada situação específica, distanciando-se, desse modo, do âmbito disciplinar, como se estrutura o currículo do PPCP. No currículo da formação docente baseada nas competências, há uma alteração no foco da aprendizagem, de modo que os conteúdos e as disciplinas passam a ter valor apenas como meios para constituição de competências. Não é isso que observamos no projeto pedagógico em análise.

Conforme as DCF, as avaliações do desempenho dos alunos também deverão incluir competências: "Tomando-se como princípio o desenvolvimento de competências para a atividade profissional, é importante colocar o foco da avaliação na capacidade de acionar conhecimentos e de buscar outros, necessários à atuação profissional" (BRASIL, 
2001b, p. 40). Esforçando-se em manter uma sintonia com o discurso desse documento, os enunciadores do PPCP (p. 58, grifo nosso) destacam que, no curso,

[...] a avaliação deve refletir a aquisição de habilidades e o desenvolvimento das competências adquiridas gradativa e permanentemente, por atividades diversas distribuídas durante o período letivo, totalizando, minimamente, três instrumentos diferentes de avaliação.

Percebe-se aí uma relação dialógica de acolhimento do discurso das DCF, que destacam também que "os instrumentos de avaliação da aprendizagem devem ser diversificados - para o que é necessário transformar formas convencionais e criar novos instrumentos" (BRASIL, 2001b, p. 40).

Nessa direção, na avaliação do licenciando em Letras, a abordagem dos aspectos cognitivos deve contemplar não apenas a aquisição do conhecimento factual, mas habilidades mais complexas relacionadas ao rol de competências estabelecidas que se almeja desenvolver no acadêmico. Esse aspecto nos incita a perguntar: quais competências serão avaliadas? Como elas serão avaliadas? Não encontramos respostas para essas questões no PPCP. Todavia, o próprio Parecer CNE/CP n. 009/2001, que fundamenta as DCF, admite dificuldade para avaliar competência, afirmando que "tendo a atuação do professor natureza complexa, avaliar as competências no processo de formação é, da mesma forma, uma tarefa complexa" (BRASIL, 2001b, p. 34). Essa situação evidencia a complexidade que envolve o conceito de competência e o paradoxo que o cerca no processo de reforma curricular, marcado por vozes em conflito.

Cabe lembrar que nas DCF, assim como nas DCL, o paradigma das competências na formação docente atende à construção de um novo tipo de professor, mais facilmente regulado no desenvolvimento de seu trabalho e acentuado nas diversas atividades que surgem na esfera escolar. $O$ discurso assentado na categoria competência presente nesses documentos é voltado para a adaptação do profissional ao mercado de trabalho, associado a uma visão mercadológica.

Na análise do PPCP, constatamos que se, por um lado, o discurso das competências não se materializa na proposta curricular do documento, por outro, os posicionamentos dos enunciadores quanto à formação voltada para o mercado de trabalho se relacionam dialogicamente de modo complementar ao discurso presente nas Diretrizes. Essa relação dialógica é perceptível no fragmento extraído do item "Justificativa da Reestruturação do Projeto Pedagógico de Curso": 
- Currículo por competências: (des)encontros entre os discursos oficial e pedagógico

Esta proposta de reestruturação curricular é, portanto, o resultado de esforços empreendidos para ofertar aos futuros profissionais de educação do estado de Mato Grosso um curso que busca estar em consonância com as teorias modernas de ensino e de aprendizagem de linguagem e línguas, além de cumprir as exigências legais de formação de professores, para atuarem no ensino fundamental e médio, assegurando a qualidade acadêmica em contexto de aceleradas mudanças na conjuntura social e no mundo do trabalho. Porém, posicionando crítica e reflexivamente em relação a inconsistências de determinados modos de pensar e 'fazer' a educação e, por extensão, a formação profissional. (PPCP, 2015, p. 14).

Os enunciadores justificam que a proposta de reestruturação curricular apresentada está "em consonância com as teorias modernas de ensino e de aprendizagem de linguagem e línguas" e, ligando argumentos em favor de uma mesma conclusão, por meio do operador argumentativo "além de", deixam claro que ela também cumpre "as exigências legais". As vozes da legalidade que ouvimos no excerto, especialmente no enunciado "assegurando a qualidade acadêmica em contexto de aceleradas mudanças na conjuntura social e no mundo do trabalho", são das DCL que assim se posicionam:

Esta proposta de Diretrizes Curriculares leva em consideração os desafios da educação superior diante das intensas transformações que têm ocorrido na sociedade contemporânea, no mercado de trabalho e nas condições de exercício profissional. (BRASIL, 2001a, p 29, grifo nosso).

Cabe observar o conectivo "porém", presente no excerto do PPCP, que marca um posicionamento mais forte no enunciado, em que prevalece a orientação argumentativa por ele iniciada de que, na sua atuação profissional, o professor saberá se posicionar de forma "crítica e reflexivamente em relação a inconsistências de determinados modos de pensar e 'fazer' a educação e, por extensão, a formação profissional". Nessa perspectiva, prevalece a ideia de uma formação que possibilite ao futuro professor a compreensão crítica da realidade educacional e do fazer educativo.

No item "concepção do curso", o documento acrescenta ainda a ideia de uma formação direcionada para a construção da cidadania consciente e ativa: "o curso pretende preparar o profissional para o mercado, mas que, através da linguagem, também saiba e vivencie os aspectos de cidadania para que se realize como profissional e como pessoa" (PPCP, 2015, p. 24, grifo nosso). 
É inquestionável como a constituição do PPCP aponta para a formação de um professor de língua materna que seja ciente de seu compromisso com a sociedade, como cidadão crítico e consciente. Por meio da ênfase constante nesse aspecto, ao longo do documento, verificamos uma constituição de currículo que, simultaneamente, se preocupa em dar plenas condições para que o licenciando ingresse no mercado de trabalho e empenha-se na sua formação para a cidadania, na formação humana, não deixando este aspecto em segundo plano.

Assim, no bojo da materialidade discursiva do documento, constatamos uma preocupação em assumir um papel muito mais concreto, intelectual, social e culturalmente, revelado, sobretudo, quando o documento se refere a "formar profissionais aptos a desenvolverem pesquisas em linguagem, bem como preparados para formar cidadãos aptos a dominarem as diferentes práticas sociais de escrita", "profissionais capazes de desenvolver uma prática didático-pedagógica com posicionamento crítico e criativo"; "críticos e comprometidos com a intervenção social"; "que tenham domínio teórico e prático na área de linguagem"; "competentes quanto ao conhecimento das teorias linguístico-literárias, estabelecendo relações entre a língua-cultura materna e a literatura brasileira e portuguesa"; "profissionais cidadãos comprometidos com o desenvolvimento social em nível local e global". Há, nesses posicionamentos, uma aspiração de assumir-se como instituição/curso a serviço da comunidade e da sociedade em geral.

Os dados evidenciam que o modelo de competências das DCL e DCF não foi concretizado na proposta curricular do PPCP, ainda que a voz defensora de tal princípio organizador do currículo não tenha deixado de ecoar na discursividade do documento. Não obstante, ecoou mais alto, no documento, a voz defensora do ensino por conteúdos, que lutou pela manutenção de certos padrões do currículo por aquisição de conhecimentos.

Desse modo, como observa Bakhtin (2014), todo enunciado aponta para a existência de jogos de poder entre as vozes que circulam socialmente. No caso do PPCP, na luta entre as vozes defensoras da organização curricular por competência, presentes nas diretrizes e as vozes do ensino por conteúdos, do currículo por aquisição de conhecimentos, a vitória, evidentemente, não foi das primeiras.

\section{Considerações finais}

Neste trabalho, analisamos a reação-resposta dos professores do Núcleo Docente Estruturante (NDE) de uma Universidade Pública mato-grossense aos discursos legais de organização do currículo com base no conceito de competência, constantes nos Pareceres 
- Currículo por competências: (des)encontros entre os discursos oficial e pedagógico

CNE/CES n. 492/2001 e CNE/CP n. 009/2001, que fundamentam, respectivamente, as Diretrizes Curriculares para os Cursos de Letras e Diretrizes Curriculares para Formação de Professores. Para verificarmos a responsividade dos professores que integram o NDE aos discursos da legalidade, examinamos o Projeto Pedagógico do Curso de Letras Português e Literatura reformulado por esses sujeitos. A pesquisa orientou-se pelos pressupostos teórico-epistemológicos e metodológicos de Bakhtin e o Círculo, o que nos possibilitou compreender os enunciados em suas dimensões discursivas.

A partir do estabelecimento de relações dialógicas entre os Pareceres, focalizando o posicionamento valorativo dos enunciadores com relação ao discurso da formação para as competências, verificamos que há uma articulação entre formação docente e mercado de trabalho, concebida de maneira pragmática e instrumental, sobretudo no Parecer que fundamenta as Diretrizes Curriculares para a Formação de Professores (DCF), no qual há a defesa de que o professor deve ter o conhecimento técnico para desempenhar sua função e, concomitantemente, investir em habilidades e competências a serem evidenciadas enquanto saber docente.

Compactuamos do entendimento de que as necessidades do mercado não podem e nem devem ser excluídas do conjunto de interesse das universidades, tendo em vista seu papel central na criação, conservação e transmissão do conhecimento. Todavia, ter presentes essas necessidades não significa transformá-las em princípio, meio e fim do ser/fazer das universidades, as quais devem exercer na integralidade sua condição de espaço privilegiado de produção de conhecimento, em que a reflexão e a análise crítica devem se instalar permanentemente. Dito de outro modo, a lógica das reformas de vinculação da educação ao mercado, calcadas no paradigma do desenvolvimento de competências, tendo como objetivo preponderante as demandas do setor produtivo, provoca o distanciamento da universidade das suas tradicionais funções.

A análise dialógica do Projeto Pedagógico do Curso de Letras Português e Literatura evidenciou que as competências não norteiam a organização curricular. Pelo contrário, o conceito aparece na materialidade discursiva do documento, mas o novo currículo não orienta a prática formativa a partir de tal conceito, tendo sido estruturado por uma listagem de disciplinas obrigatórias e específicas, evidenciando que as Diretrizes podem tomar um sentido diferente daquele proposto por seus legisladores. Percebemos no PPC analisado que há uma preocupação em atender as demandas do mercado de trabalho, mas a ênfase recai sobre um modelo formativo ancorado no princípio de uma formação teórica e prática do futuro professor, alicerçado numa base humanística e crítica da realidade. As vozes que ressoaram mais alto nesse instrumento foram as $D C L$, que são específicas para os cursos de Letras, e as das DCF, que foram revogadas em 2015. 
Vale ressaltar que cabe aos membros do NDE, na perspectiva de uma implementação participativa e de avaliações constantes dos PPCs, discutir conjuntamente uma agenda de trabalho visando à introdução de debates que abordem os limites e as possibilidades do complexo processo de reforma curricular, tomando as Diretrizes como uma oportunidade para discussões sobre o que nelas está posto e buscando possíveis cenários para o aperfeiçoamento da formação em Letras.

Os princípios organizadores do currículo constantes nas Diretrizes devem ser um dos itens centrais da discussão, a fim de se buscar caminho para a construção de projetos pedagógicos inovadores. A tarefa coletiva não pode prescindir da oportunidade de reflexão sobre as constatações de que o conceito de competência não é tomado como central na organização do currículo, nas Diretrizes de 2015, tendo sido, inclusive, apagado da discursividade do documento, mas, por outro lado, tal conceito, nas Diretrizes Curriculares para os Cursos de Letras (DCL), é nuclear na organização dos cursos e deve predominar nas propostas curriculares como eixo condutor do paradigma da formação docente.

Discutir esse impasse e outras contradições que cercam a regulamentação das Diretrizes Curriculares Nacionais para os cursos de Letras e de licenciatura, marcadas pela interseção de diferentes vozes, é requisito indispensável para construção de propostas curriculares alicerçadas em princípios orientadores que proporcionem aos futuros professores uma sólida formação teórica, contemplando distintas dimensões: científica, pedagógica, técnica, ético-moral, política, estética, entre outras.

\section{Referências}

BAKHTIN, M. M. [1934-1935]. O discurso no romance. In: BAKHTIN, M. M. Questões de literatura e de estética: a teoria do romance. 3. ed. Tradução Aurora Fornoni Bernardini et al. São Paulo: UNESP, 2014.

BAKHTIN, M. M. [1920/1922]. O autor e a personagem na atividade estética. In: BAKHTIN, M. M. Estética da criação verbal. Tradução Paulo Bezerra. 6. ed. São Paulo: Martins Fontes, 2011a. p. 03-192.

BAKHTIN, M. M. [1952-1953]. Os gêneros do discurso. In: BAKHTIN, M. M. Estética da criação verbal. Tradução Paulo Bezerra. 6. ed. São Paulo: Martins Fontes, 2011b. p. 261-306. 
- Currículo por competências: (des)encontros entre os discursos oficial e pedagógico

BRASIL. 2001a. Parecer CNE/CES 492/2001. Conselho Nacional de Educação - Institui as Diretrizes Curriculares Nacionais dos cursos de Filosofia, História, Geografia, Serviço Social, Comunicação Social, Ciências Sociais, Letras, Biblioteconomia, Arquivologia e Museologia. Brasília: Ministério da Educação. Disponível em: http://portal.mec.gov.br/ cne/arquivos/pdf/CP012002.pdf. Acesso em: 04 out. 2013.

BRASIL. 2001b. Parecer CNE/CP 009/2001, de 8 de maio de 2001. Diretrizes Curriculares Nacionais para a Formação de Professores da Educação Básica, em nível superior, curso de licenciatura, de graduação plena. Brasília: Ministério da Educação. Disponível em: http://portal.mec.gov.br/cne/arquivos/pdf/009.pdf. Acesso em: 24 jun. 2014.

BRASIL. 2010. Resolução No 01, de 17 de junho de 2010 - Comissão Nacional de Avaliação da Educação Superior - CONAES. Disponível em: http://portal.mec.gov.br/index. php?option=com_content\&view=article\&id=15712\&ltemid=1093. Acesso em: 04 out. 2013.

BRASIL. 2015. Parecer CNE/CP 002/2015, de 9 de junho de 2015. Diretrizes Curriculares Nacionais para a Formação Inicial e Continuada dos Profissionais do Magistério da Educação Básica. Brasília: Ministério da Educação. Disponível em: http:// portal.mec.gov.br/index. php?option=com_content\&view=article\&id=21123\&ltemid=866. Acesso em: 07 jul. 2015.

BRASIL. 2015b. Resolução CNE/CP 002/2015, de $1^{\circ}$ de julho de 2015. Define as Diretrizes Curriculares Nacionais para a formação inicial em nível superior (cursos de licenciatura, cursos de formação pedagógica para graduados e cursos de segunda licenciatura) e para a formação continuada. Brasília: Ministério da Educação. Disponível em: http://pronacampo. mec.gov.br/images/pdf/res_cne_cp_02_03072015.pdf. Acesso em: 07 jul. 2015.

DINIZ-PEREIRA, J. E.; LACERDA, M. P. Possíveis significados da pesquisa na prática docente: ideias para fomentar o debate. Educação e Sociedade, Campinas, v. 30, n. 109, p. 1229-1242, 2009. Disponível em: http://www.scielo.br/scielo.php?script=sci_ arttext\&pid=S0101-73302009000400015. Acesso em: 16 dez. 2016.

FREITAS, H. C. L. CNE discute Diretrizes para Formação de Professores. 2015. Disponível em: http://formacaoprofessor.com/2015/04/05/cne-discute-diretrizes-para-formacaode-professores/. Acesso em: 13 nov. 2015.

FRIGOTTO, G. (org.). Educação e crise do trabalho: perspectivas de final de século. Petrópolis: Vozes, 1998. 
GATTI, B. A.; NUNES, M. R. (org.). Formação de Professores para o Ensino Fundamental: estudo de currículos das licenciaturas em pedagogia, língua portuguesa, matemática e ciências biológicas. São Paulo: Fundação Carlos Chagas/DPE, 2009.

GONDIN, J. P.; FERNANDES, Â. M. D. Interrogações sobre políticas de formação e ensino de arte nos currículos dos cursos de pedagogia. Educação e Pesquisa, São Paulo, v. 37, n. 3, p. 497-512, 2011.

LIBÂNEO, J. C. Licenciatura em Pedagogia: a ausência dos conteúdos específicos do ensino fundamental. In: GATTI, B. A. et al. (org.). Por uma Política Nacional de Formação de Professores. São Paulo: UNESP, 2013. p. 73-94.

LIBÂNEO, J. C. Integração entre Didática e Epistemologia das Disciplinas: uma via para a renovação dos conteúdos da didática. In: DALBEN, A. et al. (org.). Convergências e Tensões no Campo da Formação e do Trabalho Docente: didática, formação de professores, trabalho docente. Belo Horizonte: Autêntica, 2010a. p. 81-104.

LIBÂNEO, J. C. O ensino da didática, das metodologias específicas e dos conteúdos específicos do ensino fundamental nos currículos dos cursos de Pedagogia. Revista Brasileira de Estudos Pedagógicos, Brasília, v. 91, n. 229, p. 562-583, 2010 b.

NUNES, J. A. Discursos (re)velados: uma análise dialógica das novas diretrizes para formação docente. Trabalhos em Linguística Aplicada, Campinas, v. 56, n. 1, p. 9-35, 2017.

PERRENOUD, P. Dez novas competências para ensinar. Porto Alegre: Artmed, 2000.

SANTOS, W. S. Organização Curricular Baseada em Competência na Educação Médica. Revista Brasileira de Educação Médica, Rio de Janeiro, v. 35, n. 1, p. 86-92, 2011.

VOLÓCHINOV, V. [1929]. Marxismo e filosofia da linguagem: problemas fundamentais do método sociológico na ciência da linguagem. Tradução Sheila Grillo e Ekaterina Vólkova Américo. São Paulo: Editora 34, 2017. 
- Currículo por competências: (des)encontros entre os discursos oficial e pedagógico

COMO CITAR ESTE ARTIGO: NUNES, Jozanes Assunção. Currículo por competências: (des)encontros entre os discursos oficial e pedagógico. Revista do GEL, v. 17, n. 3, p. 188-215, 2020. Disponível em: https://revistadogel.gel.org.br/

DOI: http://dx.doi.org/10.21165/gel.v17i3.2121

Submetido em: 29/06/2018 | Aceito em: 25/09/2020. 